\title{
Bilateral Retinal Detachment Secondary to Clomiphene Citrate
}

\author{
Anita Syla Lokaj, Blerta Rama \\ Department of Ophthalmology, University Center Clinic of Kosova, Prishtina, Kosova \\ Email: Anitasylaj@live.com, Blerta.rama@uni-pr.edu
}

How to cite this paper: Lokaj, A.S. and Rama, B. (2018) Bilateral Retinal Detachment Secondary to Clomiphene Citrate. Open Journal of Ophthalmology, 8, 31-35. https://doi.org/10.4236/ojoph.2018.81005

Received: December 17, 2017

Accepted: February 4, 2018

Published: February 7, 2018

Copyright $\odot 2018$ by authors and Scientific Research Publishing Inc. This work is licensed under the Creative Commons Attribution International License (CC BY 4.0).

http://creativecommons.org/licenses/by/4.0/

\begin{abstract}
Purpose: The purpose of this study is to assess the relationship between Clomifene citrate and retinal detachment in particular. Methods: a 42-year-old woman has developed bilateral retinal detachment after three courses of clomiphene citrate. A literature research for bilateral retinal detachment does not include this severe ophthalmologic complication. Conclusion: This is the first reported case of bilateral retinal detachment after treatment with clomiphene citrate. The caution is warranted in treating infertility patients with CC, and patient should be well informed of this side effect before prescribing this therapy by gynecologist.
\end{abstract}

\section{Keywords}

Retinal Detachment, Infertility, Clomiphene Citrate

\section{Introduction}

Retinal detachment, as well as central retinal artery occlusion, endophthalmitis, chemical burn is one of the most time-critically ocular emergencies that have been associated with various ocular and systemic conditions [1]. Although retinal detachment is a rare condition in fertility patients. Ovulatory disorders are common causes of subfertility and infertility in women of reproductive age. Several pharmacologic agents are available to induce or augment ovulation, but they have varying degrees of success. These medications include: clomiphene citrate (a selective estrogen receptor modulator), aromatase inhibitors, urinary and recombinant gonadotropins, gonadotropin-releasing hormone $(\mathrm{GnRH})$ analogs and insulin-sensitizing agents. Clomiphene citrate (clomiphene citrate tablets USP) is the medication that is orally administered, it is non-steroidal ovulatory stimulant [2] and it was prescribed as an first-line treatment, because it's many 
advantages compared to other drugs for example: its low cost, relative ease of use and minimal side effects. The drug that was created in synthetic manner the hypothalamus to release more Gonadotropin releasing hormone (GnRH), which then prompts the pituitary to release more LH and FSH and thus increasing the stimulation of the ovary to begin to produce a mature egg. Adverse events reported during the clinical trial by Merrell Dow Pharmaceuticals Inc. involving 8029 anovulatory woman include ovarian enlargement $13.6 \%$, vasomotor flushes $10.4 \%$, abdominal-pelvic discomfort, distention, bloating $5.5 \%$, nausea and vomiting $2.2 \%$, breast discomfort $5.5 \%$, visual symptoms $1.5 \%$, headache $1.3 \%$ and abnormal uterine bleeding $1.3 \%$ [3]. The efficacy of clomiphene has been observed too early and about 50 years have passed since the first research has been done and has proven that clomiphene may induce ovulation estimated at about 75 percent of cases with amenorrheic problems [4]. The first endocrine event in response to a course of clomiphene therapy is an increase in the release of pituitary gonadotrophins followed by an increase in thrombogenic estradiol.

\section{Case Report}

An 42 -year-old woman, gravida 0 , is presented with primary infertility. She has irregular menses with dysmenorrhea. She has never used before oral or other types of contraceptives. In vitro fertilization was planned and ovulation induced by clomiphene citrate $50 \mathrm{mg}$. She has undergone one cycle of the treatment (for five days) for two months before, but she stopped in the second month on day 3 . She develops visual disturbance symptoms on her right eye. These included floaters, flashes of light initially followed by sudden blurred vision and in just a few days she had complete loss of vision. She reported these symptoms to the general doctor, who advised her to visit an Ophthalmologist. Her visual acuity was $2 / 60$ in her right eye. The visual acuity (with correction) was normal in her left eye. Intraocular pressure were; $8 \mathrm{mmHg}$ in her right eye and $12 \mathrm{mmHg}$ in her left eye. Both anterior segments were normal. The initial fund oscopic features was suggestive for retinal detachment. Ultrasound B scan and optical coherence tomography of the right fundus confirmed the diagnosis; Figure 1 (B scan) and Figure 2 (photofundus). She was referred for immediate management, but she neglected instructions from ophthalmologist. She continued to use the clomiphene and the dose was increased in further cycle to $100 \mathrm{mg}$. However, on the day 3 she developed also the sudden blurry vision on her left eye. The medication was stopped and she was referred to her ophthalmologist after visual acuity has dramatically worsened. Her visual acuity was $1 / 60$ and intraocular tension was $10 \mathrm{mmHg}$. Fundus examination of her left eye showed retinal detachment that was documented by ultrasound B-scan and OCT; Figure 3 (B scan) and Figure 4 (photofundus). Systemic examination revealed no abnormalities.

\section{Discussion}

Retinal detachment is a medical emergency and remains the very important case of visual loss [5]. It is referred to separation of the neurosensory retina form the 


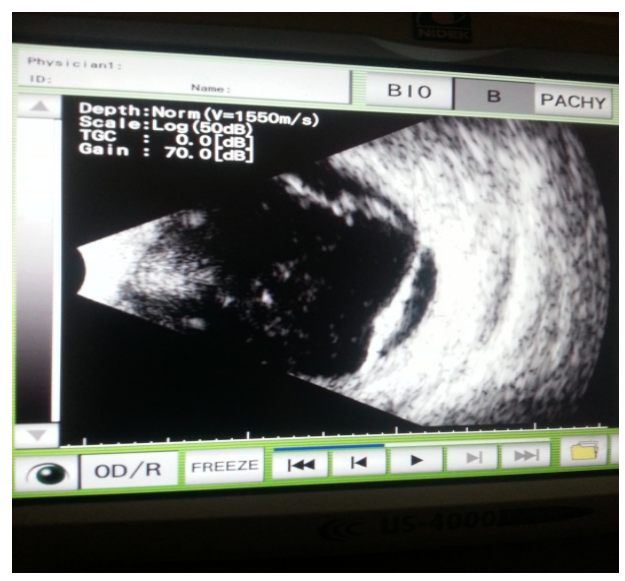

Figure 1. Ultrasound B the right eye.

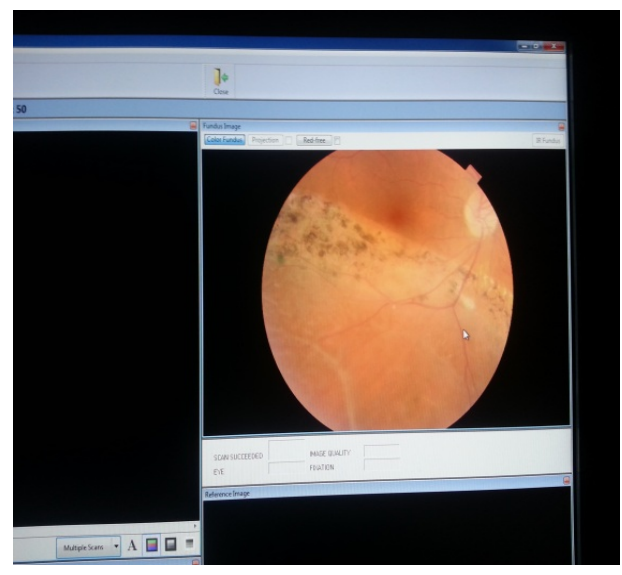

Figure 2. Optical coherence tomography of the right fundus.

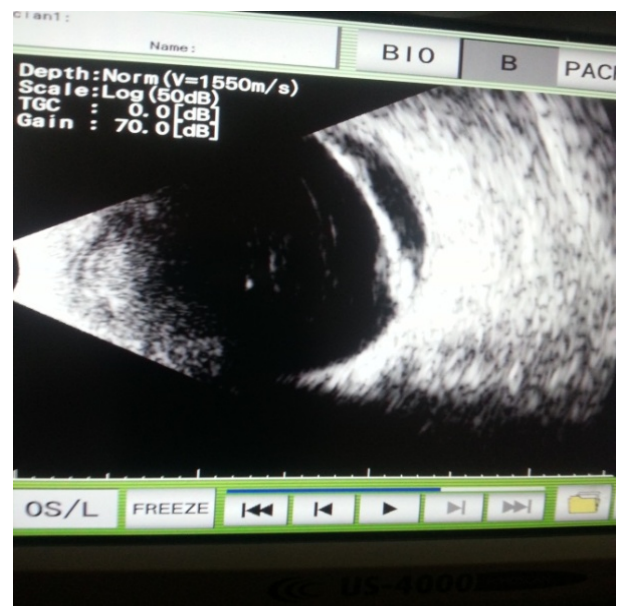

Figure 3. Ultrasound B scan of the left eye.

underlying retinal pigment epithelium [6]. Clinically, it presents with variable visual loss [7]. The exact pathogenesis of retinal detachment occurs following 3 basic mechanisms: a hole, break or tear in the neuronal layer as rhegmatogenous 


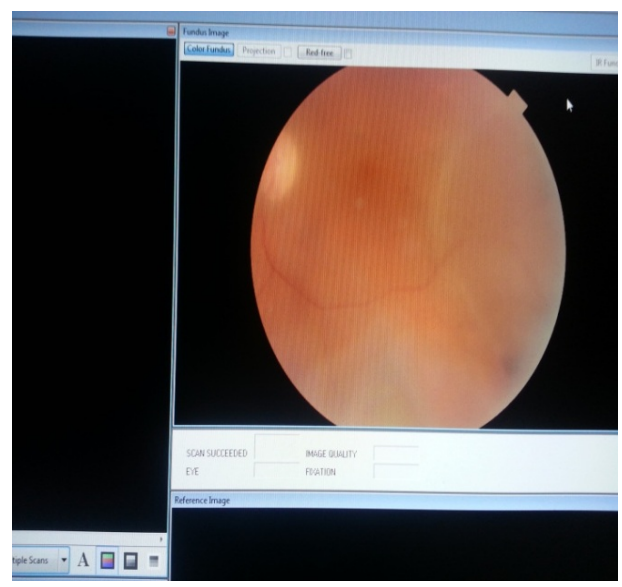

Figure 4. Optical coherence tomography of the Left fundus.

retinal detachment; traction from vascular fibrous membrane or inflammatory process on the surface of the retina as a tractional retinal detachment and exudation of material into subretinal space from retinal vessels from different diseases as vasculitis, central retinal vein occlusion etc. [8]. Various local and systemic factors play significant role in the retinal detachment. Retinal detachment is associated with various pathological diseases, including the following: congenital malformations, vascular disease, metabolic disorders, high myopia, trauma, tumors, degeneration, and abnormalities of vitreous [9]. However, retinal detachment is a rare condition in fertility patients. Thrombo-embolic complications have been reported in patients receiving clomiphene, including myocardial infarction, deep-vein thrombosis and central retinal vein occlusion [10]. There are only four known articles that describe visual problems with Clomifene citrate in fertility patients and those were published as case reports. Also, more spedifically there are found only two systematic reviews on the adverse effects of Clomifene, but described no visual changes. As far known, there are no published cases reports or studies that associate Clomifene citrate with irreversible blindness and retinal disorder or retinal detachment [11].

\section{Conclusion}

Retinal detachment is not often seen by gynecologists, but they should be aware of the condition in fertility patients undergoing induction of ovulation, especially with clomiphene citrate. We are not sure that clomiphene citrate causes retinal detachment, but in absence of other diseases we should have suspicion in this drug. It is very important to advise the patients, who are taking Clomifene citrate, to stop their treatment immediately when they encounter visual problems and they should visit an ophthalmologist for complete examinations. During our research we found one report on unilateral retinal detachment, but so far not one with bilateral retinal detachment. Therefore, it is highly recommended that patients, before starting the Clomifene citrate, undergo ophthalmologic examinations and equally important to do the following regular ophthalmic examina- 
tions after starting with the treatment with this medicament.

\section{Author's Contributions}

Anita Syla Lokaj: Substantial contributions to conception and design, Acquisition of data, Analysis and interpretation of data, Drafting the article, Revising it critically for important intellectual content, Final approval of the version to be published. Blerta Rama: Analysis and interpretation of data, Revising it critically for important intellectual content, Final approval of the version to be published.

\section{Guarantor}

The corresponding author is the guarantor of submission.

\section{Conflict of Interest}

Authors declare no conflict of interest.

\section{References}

[1] Pokhrel, P.K. and Loftus, S.A. (2007) Ocular Emergencies. American Family Physician, 76, 829-836

[2] (2017) Clomid-FDA Prescribing Information, Side Effects and Uses https://www.drugs.com/pro/clomid.html

[3] http://pdfs.semanticscholar.org/116f/0c49aac334ed87d64fe1e4c8174294c161fd.pdf

[4] Rene Moy, M.D. and Geraldine Ekpo, M.D. (2011) Clomiphene Citrate Use for Ovulation Induction: When, Why, and How? http://contemporaryobgyn.modernmedicine.com/contemporary-obgyn/news/clinic al/clinical-pharmacology/clomiphene-citrate-use-ovulation-induction-wh

[5] Schwartz, S.G., Flynn, H.W. and Mieler, W.F. (2013) Update on Retinal Detachment Surgery. Current Opinion in Ophthalmology, 24, 255-261. https://doi.org/10.1097/ICU.0b013e32835f8e6b

[6] Ghazi, N.G. and Green, W.R. (2002) Pathology and Pathogenesis of Retinal Detachment. Eye, 16, 411-421. https://doi.org/10.1038/sj.eye.6700197

[7] Levenson, J.H. and Kozarsky, A. (1990) Visual Acuity Change. In: Walker, H.K., Hall, W.D. and Hurst, J.W., Eds., Clinical Methods: The History, Physical, and Laboratory Examinations, 3rd Edition, Butterworths, Boston. http://www.ncbi.nlm.nih.gov/books/NBK215/

[8] (2017) Retinal Detachment: Practice Essentials, Background, Pathophysiology. https://emedicine.medscape.com/article/798501-overview

[9] (2017) Retinal Detachment. http://www.institut-vision.org/en/health/28-diseases/90-retinal-detachment.html?sh owall $=1$ \&limitstart $=$

[10] http://academic.sun.ac.za/Health/Media_Review/2010/MR6apr10/files/clomiphene citrate_central_retinal_vein.pdf

[11] https://www.oatext.com/pdf/CMI-2-133.pdf 